\title{
Immediate Perinatal Outcome of Neonates with Maternal Hypertensive Disorders in Pregnancy
}

\section{Hassan $\mathrm{M}^{1}$, Choudhury $\mathrm{F}^{2}$, Begum $\mathrm{M}^{3}$, Rahman $\mathrm{H}^{4}$, Akhter $\mathbf{S}^{5}$}

${ }^{1}$ Dr. Mahmuda Hassan, MBBS, MD, Associate Professor, Department of Paediatrics, ${ }^{2} \mathrm{Dr}$. Ferdousi Choudhury, MBBS, FCPS, Associate Professor and Head of Department, Obstetrics and Gynaecology, ${ }^{3} \mathrm{Dr}$. Marium Begum, MBBS, DCH, MD. Assistant Professor, Department of Paediatrics, ${ }^{4}$ Prof. Dr. Hamidur Rahman, MBBS, FCPS, Professor and Head of Department of Paediatrics, ${ }^{5}$ Prof. Dr. Sayeba Akhter, MBBS, FCPS, FRCOG, Academic Director. All from Ad-din Women's Medical College Hospital, Dhaka. Bangladesh.

\section{Introduction}

- very year nearly 5,29,000 women die - globally due to pregnancy related causes. For each death nearly 118 women suffer from life threatening events or severe acute morbidity ${ }^{1}$. Hypertensive disorders of pregnancy seem to be one of the major causes of maternal morbidity and mortality leading to $10-15 \%$ of maternal deaths specially in the developing world ${ }^{2}$. Recent work has suggested that women with mild pregnancy-induced hypertension may have improved perinatal outcomes. There may be differences in placental nutrient and oxygen transfer between hypertensive and normotensive mothers. The reduced ability of the maternal arterial supply of the placenta to autoregulate flow at the intervillous level means that changes in maternal blood pressure will be reflected within the intervillous space. Syndromes that improve perfusion at this level may improve maternalfetal transfer of nutrients and oxygen and should be reflected as improved neonatal and infant health. Certainly, a continuum must exist at which such an increase in perfusion to the villous spaces becomes maladaptive, or constitutes a "biological overshoot" and increases the risk to the mother and/or fetus. So, mild pregnancy induced hypertension may have some beneficial effect on fetus, but other than mild gestational hypertension is a leading cause of maternal and neonatal morbidity and mortality ${ }^{3}$.

\section{Address for correspondence \\ Dr. Mahmuda Hassa \\ Ad- din Medical College and Hospital \\ 2 Boro-Moghbazar, Dhaka. 1217, Bangladesh \\ Cell: +8802-01711-814940 \\ E-mail:mahmudahasn@yahoo.com}

\begin{abstract}
Introduction: Hypertensive disorders of pregnancy seem to be one of the major causes of maternal morbidity and mortality leading to $10-15 \%$ of maternal deaths especially in the developing world. This study examines the perinatal outcome of neonates with mothers having hypertensive disorder of pregnancy. Materials and Methods: Seventy three mothers and their newborn babies were selected. Mothers with Gestational hypertension, preeclampsia, eclampsia, chronic hypertension, preeclampsia superimposed on chronic hypertension were included. Gestational diabetics (GDM), chronic maternal diseases, infant of diabetic mother (IDM), babies with major congenital malformations were excluded. Results: Thirty five mothers $(47.9 \%)$ had regular antenatal check up (ANC) and 38 (52\%) had irregular. Nineteen mothers $(26 \%)$ were primipara and $54(74 \%)$ were multipara. Forty four mothers $(60 \%)$ had positive family history or had own history of hypertensive disorder during their previous pregnancy. 13 mothers (17.8\%) had normal vaginal delivery (NVD), 60 mothers (82.19\%) had lower uterine cesarean section (LUCS). 30 babies (41\%) were admitted. 44 mothers $(60 \%)$ had gestational hypertension, 21 had $(28.6 \%)$ pre-eclamtic toxemia (PET), 3 had (4.1\%) eclampsia, 5 had $(6.8 \%)$ essential hypertension 3 of them subsequently developed PET. Mean maternal age 26.86 years, gestational age $34.15( \pm 1.46)$ weeks among admitted and $36.30( \pm 1.6)$ weeks among non-admitted group. Mean birth weight was $1.69( \pm 0.39) \mathrm{kg}$. among admitted and $2.71( \pm 0.31) \mathrm{kg}$. in non-admitted babies. Seven pregnancies $(9.58 \%)$ were twin, macerated 1 twin among was among 2 pregnancies (2.7\%), 5 intra uterine death (IUD) observed in single pregnancy. Conclusion: Significant number of babies with maternal hypertensive disorder of pregnancy needed hospitalization, mean birth weight and gestational age was less than that of the non-admitted group.
\end{abstract}

Key words: Hypertensive disorder of pregnancy, neonate, outcome.

\section{How to cite this article?}

Hassan M, Choudhury F, Begum M, Rahman H, Akhter S. Immediate Perinatal Outcome of Neonates with Maternal Hypertensive Disorders in Pregnancy. J Nepal Paediatr Soc 2013;33(3):190-195. 
The hypertensive mothers were divided into the following groups:

Gestational hypertension: Hypertension manifested after 20 weeks of gestation.

Pre-eclampsia/pre-ecpamptic toxemia (PET): Hypertension associated with proteinuria greater than $0.3 \mathrm{~g}$ in a twenty four hour urine collection or greater than $1 \mathrm{~g} / \mathrm{L}$ in a random sample.

Essential hypertension: The presence of sustained blood pressure of $140 / 90 \mathrm{~mm} \mathrm{Hg}$ or higher before pregnancy or before twenty weeks of gestation.

Pre-eclampasia superimposed on essential hypertension : Pre-eclampasia diagnosed in a previously hypertensive women ${ }^{4}$.

Eclampsia: Pre-eclampsia when complicated with convulsion and/or coma.

The term pregnancy induced hypertension $(\mathrm{PIH})$ is defined as the hypertension that develops as a direct result of the gravid state. It includes (i) Gestational hypertension, (ii) Pre-eclampasia, (iii) Eclampsia 5 .

Hypertensive disorders of pregnancy (HDP) predispose women to acute or chronic utero-placental insufficiency, resulting in ante or intra-partum asphyxia that may lead to fetal death, intrauterine growth retardation and/or preterm delivery ${ }^{6,7}$.

The offspring of women with hypertension during pregnancy experience higher rates of prematurity and low birth weight compared to healthy maternal controls. Expectant management with temporizing treatment should be performed to lengthen gestation, which may be associated with enhanced perinatal survival. Maternal and fetal surveillance is conducted at regular intervals and delivery is indicated for worsening maternal and foetal conditions ${ }^{8}$. Special neonatal care is required for such babies, which is associated with emotional and financial stress for both parents and third party payers and long-term infant developmental consequences ${ }^{9}$.

Moreover the disease not only affects pregnancy outcome but also predisposes mother and child to long term health complications like cardiovascular disease ${ }^{10}$. The aim of the study was to see the immediate perinatal outcome of neonates with maternal hypertensive disorders of pregnancy.

\section{Materials and Methods}

This prospective study was done at Ad-din Medical College and Hospital from $1^{\text {st }}$ January 2012 to June $30^{\text {th }}$ 2012 at the department of Obstetrics and Gynecology to see the perinatal outcome of neonates with maternal hypertensive disorders in pregnancy. Seventy three cases with maternal history gestational hypertension, pre-eclampasia, essential hypertension, pre-eclampasia superimposed on essential hypertension or eclampsia admitted for the delivery were taken for the study. While all those patients who gave history of raised blood pressure prior to 20 weeks of gestation or those mothers taking treatment for control of blood pressure prior to 20 weeks of pregnancy were assumed to be chronic hypertension. Patients with pre-gestational chronic hypertension who were taking treatment were also included irrespective of their blood pressure reading at the time of admission.

Data regarding the demographic parameters like antenatal check up, parity, gestational age, time of onset of raised blood pressure, associated medical disorders specially the history of hypertensive disorder during their previous pregnancy, family history of hypertension, preterm labour, mode of delivery, and fetal complications like intra uterine death (IUD) were recorded in a structured questionnaire. Neonatal parameters like gestational age, birth weight, sex, respiratory distress due to respiratory distress syndrome (RDS), congenital pneumonia, meconium aspiration syndrome (MAS), perinatal asphyxia with convulsion were also recorded. Gestational age (GA) were categorized as pre-term when $\mathrm{GA}<37$ completed weeks, term when GA between 37 to 42 completed weeks, post term when GA $>42$ weeks. Birth weight were categorized as normal birth weight. (2.5 to $4 \mathrm{~kg}$ ), low birth weight (LBW) $<2.5 \mathrm{~kg}$, (up to and including 2499gms), Very low birth weight (VLBW) $<1.5 \mathrm{~kg}$, (up to and including 1499gms), extremely low birth weight baby (ELBW) < 1000gm (up to and including 999gms). Intra uterine growth retardation (IUGR) when the birth weight was less than $10^{\text {th }}$ percentile for the gestational weight.

Mothers with diabetes mellitus (DM), gestational diabetes mellitus (GDM), chronic diseases like chronic renal and chronic liver diseases, endocrine and collagen diseases were excluded from the study. Babies with major congenital malformations were also excluded from the study. Statistical analyses of clinical and demographic factors were carried out by $\mathrm{X}^{2}$ test. Data was analyzed with SPSS version 17. $p$-value less than 0.05 was considered statistically significant.

\section{Results}

Total 73 mothers with their babies were selected for the study. Mean maternal age was 26.86 years. Total male babies were 40 and female 33 .

Highly significant values for the HDP were observed among the multi-para women. Significant number of 
mother had irregular ANC or no ANC at Ad-din hospital. Number of LUCS and the NICU admission were highly significant ( $p$-value <0.001). Significant number of mothers had own history of HDP during their previous pregnancy or had positive family history of hypertension $(p$-value $<0.01)$.

This pie diagram shows type of hypertensive disorder during pregnancy. $44(60 \%)$ mother had gestational hypertension, 21 (29\%) had PET, eclampsia $3(4 \%)$ and essential hypertension were $5(7 \%), 3$ of them subsequently developed PET. Gestational hypertension was the major hypertensive disorder followed by preeclamptic toxemia.

Overall there was male preponderance. Males 40, females 33, Ratio M:F = 1.2:1. There is male preponderance in admitted group. Eighteen (60\%) males and females $12(40 \%)$ than that of the non admitted group. In non-admitted group number of male $22(51.15 \%)$ and female $21(48.83 \%)$, is almost equal.

Mean birth weight and gestational age was low in admitted group and which was highly significant
( $p$-value $<0.001)$. Incidence of preterm/near term was significantly high in admitted group ( $p$-value 0.01). No AGA seen in admitted group. Low birth weight baby ( $p$ value 0.01 ), VLBW ( $p$ value 0.001 ), IUGR, were significantly high in the admitted group ( $p$ value 0.004 ) and the number of term delivery was low in admitted group and the $p$-value was also not significant ( $p$-value 0.08 ). Significant number of mothers had positive family of hypertension or had own history of hypertensive disorder in previous pregnancy ( $p$-value 0.01$)$. No term appropriate for gestational age (AGA) (>2.5 kg) babies were found in the admitted group ( $p$-value 0.001).

This diagram shows babies needed NICU admission had history of respiratory distress 18 (60\%), perinatal asphyxia (PNA) 6 (20\%), meconium aspiration syndrome (MAS) 10(33.33\%), $30(100 \%)$ to rule out (R/O) sepsis. $7(9.58 \%)$ pregnancies were twin, macerated 1 twin among $2(2.7 \%)$ pregnancies, $5(6.84 \%)$ intrauterine death (IUD) in single pregnancies. Two $(6.6 \%)$ babies expired during the course of treatment at NICU out of 30 babies. Total peri-natal death was 9 (12.32\%).

Table 1: Maternal Demographic profile

\begin{tabular}{|l|c|c|c|c|c|}
\hline & & & Total & $X^{2}$ & $p$-value \\
\hline ANC & With ANC 35 (47.9\%) & Irregular or no ANC 38 (52\%) & 73 & 5.45 & $<0.001$ \\
\hline Parity & Primi 19 (26\%) & Multi 54 (74\%) & 73 & 33.56 & $<0.001$ \\
\hline Family H/O/past H/O/HTN/HDP & $44(60.27 \%)$ present & $29(39.72 \%)$ absent & 73 & 6.16 & 0.01 \\
\hline Mode of delivery & $60(82.19 \%)$ LUCS & $13(17.80 \%)$ NVD & 73 & 60.52 & $<0.001$ \\
\hline NICU admission & $30(41 \%)$ needed & $43(59 \%)$ not needed & 73 & 4.63 & 0.001 \\
\hline
\end{tabular}

Table 2: Sex distribution of the admitted and the non admitted groups of neonates in relation to gestation and birth weight $(n=73)$.

\begin{tabular}{|l|c|c|c|c|c|}
\hline & \multicolumn{2}{|c|}{ Admitted Group. 30 } & \multicolumn{2}{c|}{ Non-admitted Group. 43 } & Total \\
\hline & $\mathbf{M}$ & $\mathbf{F}$ & $\mathbf{M}$ & $\mathbf{F}$ & \\
\hline Term $(>37 \mathrm{wks})$ & $6(20 \%)$ & $4(13.33 \%)$ & $14(32.55 \%)$ & $13(30.23 \%)$ & $37(50.68 \%)$ \\
\hline Pre/near term $(<37 \mathrm{wks})$ & $12(40 \%)$ & $8(26.66 \%)$ & $8(18.60 \%)$ & $8(18.60 \%)$ & $36(49.31 \%)$ \\
\hline Term AGA $(>2.5 \mathrm{~kg})$ & $(0 \%)$ & $(0 \%)$ & $10(23.25 \%)$ & $12(27.90 \%)$ & $22(30.13 \%)$ \\
\hline LBW $(1.5$ to $2.5 \mathrm{~kg})$ & $12(40 \%)$ & $10(33.32 \%)$ & $12(27.90 \%)$ & $9(20.93 \%)$ & $43(58.90 \%)$ \\
\hline VLBW $(<1.5 \mathrm{~kg})$ ELBW $(<1.0 \mathrm{~kg})$ & $6(20 \%)$ & $2(6.66 \%)$ & 0 & 0 & $08(10.95 \%)$ \\
\hline IUGR/SGA & $6(20 \%)$ & $5(16.66 \%)$ & $2(4.65 \%)$ & 0 & $13(17.80 \%)$ \\
\hline
\end{tabular}


Table 3: Neonatal Demographic profile

\begin{tabular}{|l|c|c|c|c|c|}
\hline & Admitted Gr. 30 & Non-admitted Gr. 43 & Total & $\mathbf{X}^{2}$ & $p$-value \\
\hline Mean Wt in kg. & $1.69( \pm 0.39)$ & $2.71( \pm 0.31)$ & & $<0.001$ \\
\hline Mean GA in weeks & $33.15( \pm 1.46)$ & $36.30( \pm 1.6)$ & & $<0.001$ \\
\hline Term $(>37$ wks) & $10(33.33 \%)$ & $27(62.79 \%)$ & $37(50.68 \%)$ & 17.05 & 0.08 \\
\hline Pre term/near term $(<37 w k s)$ & $20(66.66 \%)$ & $16(37.20 \%)$ & $36(49.31 \%)$ & 6.13 & 0.01 \\
\hline Term AGA (>2.5kg) & $0(0 \%)$ & $22(51.16 \%)$ & $22(30.13 \%)$ & 25.3 & $<0.001$ \\
\hline LBW $(1.5$ to $2.5 \mathrm{~kg})$ & $22(73.32 \%)$ & $21(48.83 \%)$ & $43(58.90 \%)$ & 4.38 & 0.01 \\
\hline VLBW $(<1.5 \mathrm{~kg}) /$ ELBW $(<1.0 \mathrm{~kg})$ & $08(26.66 \%)$ & 0 & $08(10.95 \%)$ & 16.0 & 0.001 \\
\hline IUGR/SGA & $11(36.66 \%)$ & $02(4.65 \%)$ & $13(17.80 \%)$ & 12.46 & 0.004 \\
\hline $\begin{array}{l}\text { F/H/ HTN+own H/O HDP in } \\
\text { previous pg. }\end{array}$ & $23(76.66 \%)$ & $21(48.83 \%)$ & $44(60.27 \%)$ & 5.72 & 0.01 \\
\hline
\end{tabular}

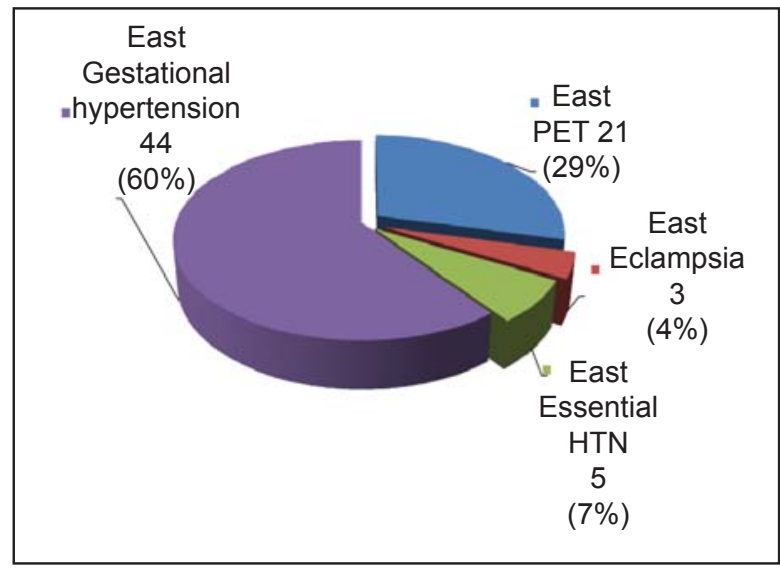

Fig 1: Types of maternal hypertensive disorder observed

\section{Discussion}

Hypertensive disorder of pregnancy is one of the major health problems among the pregnant mothers. It is also considered to be a major worldwide health problem causing an increased risk of perinatal and maternal morbidity and mortality ${ }^{11}$.

The prevalence of HDP varies according to geographic regions of world and ranges from $1.5 \%$ in Sweden to $7.5 \%$ in Brazil ${ }^{12}$. Some studies from Saudi Arabia reported prevalence between $2.6 \%$ and $3.7 \%{ }^{13}$ while Venture determine a prevalence of $3.8 \%$ in USA in $2000^{14}$. The incidence reported from Turkey was $8.49 \%{ }^{15}$.

In our study gestational hypertension 44 (60\%) was the major hypertensive disorder observed, essential hypertension was the least 5 (6.8\%). Other study also showed essential hypertension cases were less, probably because majority of the mothers did not receive antenatal care and were admitted as emergency cases with raised blood pressure and had history of hypertension before this pregnancy and no blood pressure record during the antenatal period was available $^{3}$, in our study $38(52 \%)$ mothers had irregular ANC or un-booked at our hospital.

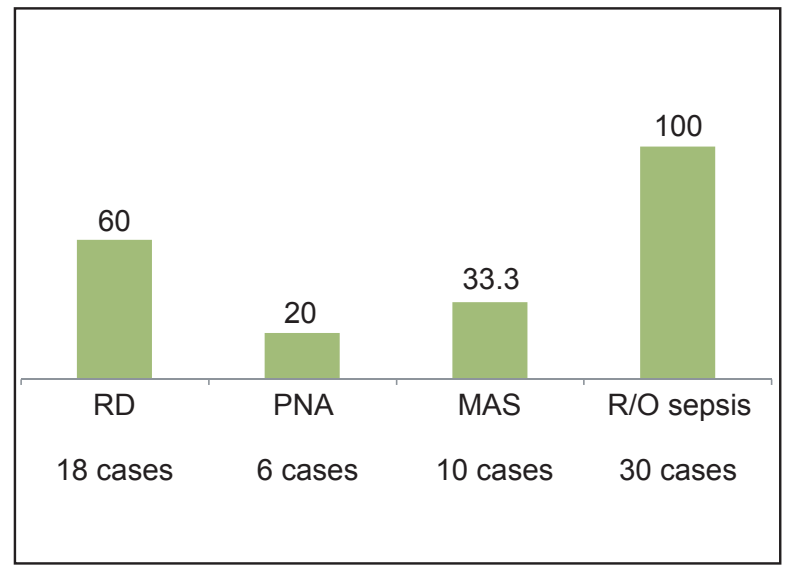

Fig 2: Shows causes for admission and the percent distribution

Age has an important influence on the incidence of hypertensive disorders of pregnancy. Young primigravidae under 20 years and patients over 30 years have an increased chance of hypertension and hence a higher perinatal mortality. This could be because the majority of conceptions take place in this age group. But in this study mean maternal age was 26.86 years and majority of the pregnancy occured between the age of 20 to 30 years. Hypertensive disorder of pregnancy is a disease of primi-para ${ }^{16,17}$. But our study showed a problem among the multi-para was 54 (74\%).

Hypertensive disorders of pregnancy predispose women to acute or chronic utero-placental insufficiency, resulting in ante or intra-partum hypoxia or anoxia that may lead to intrauterine growth retardation and/or preterm delivery even fetal death.

In this study preterm/near term delivery was 20 $(66.66 \%)$ vs. $16(37.20 \%)$ and low birth weight babies $22(73.32 \%)$ vs. $21(48.83 \%)$, VLBW was $8(26.66 \%)$ vs. $0(0 \%)$ in admitted vs. non-admitted group respectively. In different studies prematurity and low birth weight was the major cause of NICU admission among the babies with maternal history of hypertensive disorder of pregnancy ${ }^{18,19,20}$ Prematurity was the most important 
factor responsible for increased perinatal morbidity and mortality which is in accordance with earlier reports ${ }^{18}$. Our study IUGR was $13(17.80 \%)$ which is higher than other studies $9.5 \%{ }^{21}$.

Birth asphyxia was the commonest neonatal complication in another study ${ }^{19}$, but in our study $18(60 \%)$ admission was due to respiratory distress, meconium aspiration syndrome was among 10 (33.33\%) and PNA was the least $6(20 \%)$ were the cause of admission at NICU. Sepsis screening was done in all $30(100 \%)$ cases in our study by doing blood culture along with other base line investigations just after admission. 30 (40\%) needed admission out of 73 neonates. High need for NICU admission was also seen in another study ${ }^{21,22 .}$

In this study $44(69.27 \%)$ mothers had hypertensive disorder during their previous pregnancy or had positive family history of hypertension, out of them $23(76.66 \%)$ in admitted and $21(48.83 \%)$ in non admitted group. Same observation was reported in other literature ${ }^{23}$. Operative delivery is reported to be increased in hypertensive disorders of pregnancies ${ }^{24}$. In our study delivery route did not differ from the literature, $60(82.19 \%)$ needed LUCS. In this study total perinatal mortality was 9 $(12.32 \%)$, out of them, macerated one twin among 2 pregnancies $(2.7 \%), 5$ IUD $(6.84 \%)$ in single pregnancy. $2(6.6 \%)$ babies expired during the course of treatment at NICU out of 30 babies. In another study, where total perinatal death was $68(15.9 \%)$ out of $427,40(31.1 \%)$ was early neonatal deaths and $28(6.5 \%)$ still births ${ }^{3}$.

\section{Conclusion}

Hypertensive disorders of pregnancy remains an important cause of fetal and neonatal morbidity and mortality which is observed in this study. Significant number of babies were delivered by caesarian section and needed hospitalization. This is a major obstetric problem has a variable degrees of neonatal involvement, we observed mean birth weight, mean gestational age was less, IUGR was high in admitted group than that of the non admitted group.

Acknowledgements: We are grateful to the department of Obstetrics and Gynaecology and Neonatal intensive care unit of Ad-din Medical College Hospital

\section{Funding: None}

Conflict of Interest: None

Permission from IRB: Yes

\section{References}

1. Waterston M, Bewley S, Wolfe C. Incidence and predictors of sever obstetric morbidity: case control study. BMJ 2001;322:1089-93.
2. Vigil-De Gracia P, Montufar-Rueda C, Ruiz J. Expectatnt management of severe preeclampsia and preeclampsia superimposed on chronic hypertension between 24 and 34 weeks gestation. Eur J Obstet Gynecol Reprod Biol 2003;107(1): 247.

3. Nadkasrni J, Bahl J, Parekh P. Perinatal outcome in pregnancies associated Hypertension. Indian Pediatr 2001;38:174-78.

4. National High Blood Pressure Education Program Working group.Report of the National High Blood Pressure Education Program working group on High Blood Pressure in pregnancy. Am J Obstet Gynecol 2000;183:S1-S22.

5. D. C Datta's Hypertensive disorders of pregnancy. Hiralal Konar, Editor, Text book of obstetrics. $17^{\text {th }}$ edition. New Central Book Agency $(P)$ Limited; $2011 ; 219-220$.

6. Naeye RL, Friedman EA. Causes of perinatal death associated with gestational hypertension and proteinuria. Am J Obstet and Gynaecol 1979;133(1);8-10.

7. Tranquilli AL, Giannubilo SR. The 'weight' of foetal growth restriction in 437 hypertensive pregnancies. Arch Gynecol Obstet 2004;270:214-6.

8. Gaugler-Senden IP, Huijssoon AG, Visser W, Styeegers EA, de Groot CJ. Maternal and perinatal outcome of preeclampsia with an onset before 24 weeks' gestation. Audit in a tertiary referral center. Eur J Obstet Gynecol Reprod Biol 2006;128:216-21.

9. Markestad T, Vik T, Ahlsten G, Gebre-Medhin $M$, Skjaerven R, Jacobsen $G$, et al. Small-forgestational-age (SGA) infants born at term: growth and development during the first year of life. Acta Obstet Gynecol Scand Suppl 1997;165:93-101.

10. Bellamy L, Casas JP, Hingorani AD, Williams DJ. Preeclampsia and risk of cardiovascular disease and cancer in later life: systematic review and metaanalysis. BMJ 2007;335:974-77.

11. Bombrys AE, Barton JR, Habli M, Sibai BM. Expectant management of severe preeclampsia at $270 / 7$ to $336 / 7$ weeks' gestation: maternal and perinatal outcomes according to gestational age by weeks at onset of expectant management. $A m \mathrm{~J}$ Perinatol 2009;26:441-46.

12. Gaio DS, Schmidt MI, Duncan BB, Nucci LB, Matos MC, Branchtein L. Hypertensive disorders in pregnancy: frequency and associated factors in a cohort of Brazilian women. Hypertens Pregnancy 2001;20(3):269-81.

13. Al-Ghamdi Saeed MG, Al-Harbi AS, Khalil A, Elyahya AR.Hypertensive disorders of pregnancy: 
prevalence, classification and adverse outcomes in northwestern Saudi Arabia. Ann Saudi Med $J$ 1999;19:6:557-60.

14. Ventura SJ, Martin JA, Cortin SG, Mathews TJ, Park MM.Births 2000; final data for 1998 national vital statistics. Reports 58 (No.3).

15. Yucesoy G, Ozkan S, Bodur H, Tan T, Caliskan E, Vural B, Coraker A. Maternal and perinatal outcome in pregnancies complicated with hypertensive disorders of pregnancy: a seven year experience of tertiary care centre. Arch Gynecol Obstet 2005;27(1):43-9.

16. Deorari AK, Arora NK, Paul VK, Singh M. Perinatal outcome in hypertensive disease of pregnancy. Indian Pediatr 1985;22:877-81.

17. Joshi N, Pandit SN, Shah PK, Vaidya PR. A study of pre-eclampsia toxemia in pregnancy. Indian $J$ Obstet Gynecol 1990;40:506-509.

18. Upadhyay SN. Obstetric problems in rural India. Indian J Obstet Gynecol 1975;25:135-39.
19. Yadav S, Saxena U, Yadav R, Gupta S. Hypertensive disorders of pregnancy and maternal and fetal outcome: A case controlled study. J Indian Med Assoc 1997;95:548-51.

20. Ara J, Jamal M, Sultana N. Perinatal outcome in pregnancy induced hypertensive mothers. Pak Armed Forces Med J 2004;54(8):76-8.

21. Ayaz A, Muhammad T, Hussain SA, Habib S. Neonatal Outcome in Pre-Eclamptic patients. J Ayub Med Coll Abbottabad 2009;21(2):53-55.

22. Walsh SW. What causes endothelial cell activation in preeclamptic women? Am J Pathol 2006;169:1104106.

23. Chesley LC, Annitto JE, Cosgrove RA. The familial factors in toxemia of pregnancy. Obstet Gynecol 1968;32:303-311.

24. Goften EN, Capewel V, Natale R, Gratton RJ. Obstetrical intervention rates and maternal and neonatal outcomes of women with gestational hypertension. Am J Obstet Gynecol 2001;185:798803. 